ISSN No. 0974-035X

An indexed refereed \& peer-reviewed journal of higher education

Towards Excellence

UGC-HUMAN RESOURCE DEVELOPMENT CENTRE

Gujarat University, Ahmedabad-380009, Gujarat, India

\title{
THE GROWTH FACTORS OF TELECOM INDUSTRY IN INDIA
}

\author{
Mr. Bhavik Barot \\ Dr Gurudutta P Japee
}

\begin{abstract}
Globalization, privatization and liberalization accelerated all round reforms in many sectors, especially in developing economies, in the world. Developing countries- like India have realized the importance of communication in the later part of 20th century. According to DoT (2020), today Indian Telecommunication Sector is one of the fastest growing telecom sectors and it has become the second largest network in the world, next to China. The Government of India really has encouraged the telecom sector to penetrate in the new markets across the country by adopting appropriate policies.
\end{abstract}

Therefore this sector is found to be in a growing path and with its potential will continue to do so in the future also. Keeping these in view, the present study analyzes the history \& evolution of Indian Telecom Sector, its growth \& developments in present scenario along with the future opportunities of the sector in India.

\section{Key words: Indian Telecom Circle, Growth \& Development, Service Providers, Market} share.

\section{Introduction}

Currently, India is the world's second-largest telecommunications market with a subscriber base of 1.16 billion and has registered strong growth in the last decade. The Indian mobile economy is growing rapidly and will contribute substantially to India's Gross Domestic Product (GDP) according to a report prepared by GSM Association (GSMA) in collaboration with Boston Consulting Group (BCG). In 2019, India surpassed the US to become the second largest market in terms of number of app downloads.

The liberal and reformist policies of the Government of India have been instrumental along with strong consumer demand in the rapid growth in the Indian telecom sector. The Government has enabled easy market access to telecom equipment and a fair and proactive regulatory framework, which has ensured availability of telecom services to consumer at affordable prices. The deregulation of Foreign Direct Investment (FDI) norms have made the sector one of the fastest growing and the top five employment opportunity generator in the country.

Objectives of the study: 
The objectives of the research study are-

1. To study the growth factor of the Telecom Sector in India.

2. To study the present trends and future growth opportunities of the Telecom Sector in India.

\section{Methodology:}

It is based on secondary data collected from the Department of Telecommunication, Telecom Regulatory Authority of India, Ministry of Communication, the reports from Government of India and other sources. In order to study the specified objectives, statistical tool like yearwise Percentage of market share of different service provider, annual growth rate and percentage were calculated.

\section{Market Size}

India ranks as the world's second largest market in terms of total internet users. The total number of internet subscribers increased to 757.61 million in January 2021. The total wireless or mobile telephone subscriber base increased to 1,163.41 million in January 2021, from 1,153.77 million in December 2020.

India is also the world's second-largest telecommunications market. The total subscriber base in the country stood at 1,183.49 million, as of January 2021.

Gross revenue of the telecom sector stood at Rs. 68,228 crore (US\$ 9.35 billion) in the third quarter of FY21.

Over the next five years, rise in mobile-phone penetration and decline in data costs will add 500 million new internet users in India, creating opportunities for new businesses.

\section{Investment/Major Development}

With daily increasing subscriber base, there have been a lot of investment and development in the sector. FDI inflow into the telecom sector during April 2000 - December 2020 totalled US\$ 37.62 billion according to the data released by Department for Promotion of Industry and Internal Trade (DPIIT).

Some of the developments in the recent past are:

- In April 2021, Elon Musk's SpaceX has started accepting pre-orders for the beta version of its Starlink satellite internet service in India for a fully refundable deposit of US\$ 99. Currently, Department of Telecommunications (DoT) is screening the move and more developments will be unveiled soon.

- In March 2021, Vodafone Idea Ltd. (VIL) announced that the acquired spectrum in five circles would help improve 4G coverage and bandwidth, allowing it to offer 'superior digital experience' to customers.

- In March 2021, Advanced Television Systems Committee (ATSC) and Telecommunications Standards Development Society, India (TSDSI) signed a deal to boost adoption of ATSC standards in India in order to make broadcast services available on mobile devices. This allows the TSDSI to follow ATSC standards, fostering global digital broadcasting standard harmonisation. 
- In December 2020, BSNL, in partnership with Skylotech India, announced a breakthrough in satellite-based NB-IoT (Narrowband-Internet of Things) for fishermen, farmers, construction, mining and logistics enterprises.

- In the first quarter of FY21, customer spending on telecom services increased $16.6 \% \mathrm{y}$-o$y$, with over three-fourths spent on data services. This spike in consumer spending came despite of the COVID-19 disruption and lack of access of offline recharges for a few weeks

- India had over 500 million active internet users (accessed Internet in the last one month) as of May 2020.

- In June 2020, Jio Platforms Ltd. sold 22.38\% stake worth Rs 1.04 trillion (US\$ 14.75 billion) to ten global investors in a span of eight weeks under separate deals, involving Facebook, Silver Lake, Vista, General Atlantic, Mubadala, Abu Dhabi Investment Authority (ADIA), TPG Capital and L. Catterton. This is the largest continuous fundraise by any company in the world.

\section{Government Initiatives:}

The Government has fast-tracked reforms in the telecom sector and continues to be proactive in providing room for growth for telecom companies. Some of the key initiatives taken by the Government are as follows:

- The Rs. 12,195 crore (US\$ 1.65 billion) production-linked incentive (PLI) scheme or telecome is expected to bring in investment of around Rs. 3,000 crore (US\$ 400.08 million) and generate huge direct and indirect employment.

- In April 2021, the government pointed out that firms such as Ericsson and Nokia are now eager to expand their operations in India, and global companies like Samsung, Cisco, Ciena and Foxconn have expressed interest to set up their manufacturing base in the country for telecom and networking products.

- In March 2021, TEPC (Telecom Equipment Export Promotion Council) organised India Telecom 2021 - a platform for convergence of technologies and business exchange.

- The Union Cabinet approved Rs. 12,195 crore (US\$ 1.65 billion) production-linked incentive (PLI) scheme for telecom \& networking products under the Department of Telecom.

- In 2021-22, the Department of Telecommunications has been allocated Rs. 58,737.00 crore (US\$ 8 billion). 56\% allocation is towards revenue expenditure and the remaining $44 \%$ is towards capital expenditure.

- Under Union Budget 2021-22, the government allocated Rs. 14,200 crore (US\$ 1.9 billion) for telecom infrastructure that entails completion of optical fibre cable-based network for Defence services, rolling out broadband in 2.2 lakh panchayats and improving mobile services in the North East.

- On January 15, 2021, India and Japan signed an MoU to enhance cooperation in the field of Information and Communications Technologies. The MoU was signed between the Union Minister for Communications, Electronics and IT, Ravi Shankar Prasad, and the Japanese Minister for Internal Affairs and Communications, Takeda Ryota. 
- On January 6, 2021, the Department of Telecommunications (DoT) issued Notice Inviting Applications (NIA) for auction of Spectrum in $700 \mathrm{MHz}, 800 \mathrm{MHz}, 900 \mathrm{MHz}$, 1,800 MHz, 2,100 MHz, 2,300 MHz and 2,500 MHz bands. Last date for submission of applications for participation in the auction is February 5, 2021, and auction to commence online from March 1, 2021.

- In December 2020, the Union Cabinet, chaired by the Prime Minister, Mr. Narendra Modi, approved a proposal by Department of Telecommunications for setting up of Public Wi-Fi Networks by Public Data Office Aggregators (PDOAs) to provide public Wi-Fi services through Public Data Offices (PDOs).

- In December 2020, the Union Cabinet, chaired by the Prime Minister, Mr. Narendra Modi, approved the provision of submarine optical fibre cable connectivity between Mainland (Kochi) and Lakshadweep Islands (KLI Project).

- On November 4, 2020, The Union Cabinet, chaired by the Prime Minister, Mr. Narendra Modi, approved to sign a Memorandum of Understanding (MoU) between the Ministry of Communication and Information Technology and the Department of Digital, Culture, Media and Sports (DCMS) of United Kingdom Government on cooperation in the field of telecommunications/information and communication technologies (ICTs).

- On September 21, 2020, Prime Minister, Mr. Narendra Modi launched a project to connect all 45,945 villages in Bihar with optical fibre internet service. This project will be completed by March 31, 2021 at a cost of Rs. 1,000 crore (US\$ 135.97 million); Rs. 640 crore (US\$ 87.01 million) of capital expenditure will be funded by Department of Telecommunications.

- In March 2020, the government approved the Production Incentive Scheme (PLI) for Large- scale Electronics Manufacturing. The scheme proposes production-linked incentive to boost domestic manufacturing and attract large investments in mobile phone manufacturing and specified electronic components including Assembly, Testing, Marking and Packaging (ATMP) units.

- $\quad$ FDI cap in the telecom sector has been increased to $100 \%$ from $74 \%$; out of $100 \%, 49 \%$ will be done through the automatic route and the rest will be done through the FIPB approval route. FDI of up to $100 \%$ is permitted for infrastructure providers offering dark fibre, electronic mail and voice mail.

Growth Factor:

India is the world's second-largest telecommunications market. The telecom market can be split into three segments - wireless, wireline and internet services. The total subscriber base in the country stood at 1,183.49 million, as of January 2021. The teledensity of rural subscribers increased to $59.50 \%$ in January 2021, from 59.05\% in December 2020, showcasing significant growth potential in demand from the rural sector.

The total wireless or mobile telephone subscriber base increased to $1,163.41$ million in January 2021, from 1,153.77 million in December 2020. 
India is also the second largest country in terms of internet subscribers. India is one of the biggest consumer of data worldwide. As per TRAI, average wireless data usage per wireless data subscriber was 11 GB per month in FY20. App downloads in the country increased from 12.07 billion in 2017 to 19 billion in 2019 and is expected to reach 37.21 billion by 2022F. The total wireless data usage in India grew $1.82 \%$ quarterly to reach $25,227 \mathrm{~PB}$ in the third quarter of FY21. The contribution of $3 \mathrm{G}$ and $4 \mathrm{G}$ data usage to the total volume of wireless data usage was $2.81 \%$ and $96.48 \%$, respectively, in the third quarter of FY21. Share of $2 \mathrm{G}$ data usage stood at $0.71 \%$ in the same quarter.

Gross revenue of the telecom sector stood at Rs. 68,228 crore (US\$ 9.35 billion) in the third quarter of FY21. Strong policy support from the Government has been crucial to the sector's development. Foreign Direct Investment (FDI) cap in the telecom sector has been increased to $100 \%$ from $74 \%$. FDI inflows in the telecom sector stood at US\$ 37.62 billion from April 2000 to December 2020.

According to a Zenith Media survey, India is expected to become the fastest-growing telecom advertisement market, with an annual growth rate of $11 \%$ between 2020 and 2023 .

The Government of India, through its National Digital Communications Policy, foresee investment worth US\$ 100 billion in the telecommunications sector by 2022. The government is encouraging global telecom network manufacturers such as Ericsson, Nokia, Samsung and Huawei to manufacture all their equipment in India with $100 \%$ local products. In March 2021, TEPC (Telecom Equipment Export Promotion Council) organised India Telecom 2021 - a platform for convergence of technologies and business exchange.

The Union Cabinet approved Rs. 12,195 crore (US\$ 1.65 billion) production-linked incentive (PLI) scheme for telecom \& networking products under the Department of Telecom.

F- Forecast, PB - Petabytes

\section{Major Market Players:}

Airtel: Bharti Airtel Limited is a leading global telecommunications company with operations in 16 countries across Asia and Africa. It is headquartered in New Delhi, India. The company ranks amongst the top three mobile service providers globally in terms of subscribers. In India, the company's product offerings include $2 \mathrm{G}, 3 \mathrm{G}$ and $4 \mathrm{G}$ wireless services, mobile commerce, fixed line services, high speed home broadband, DTH, enterprise services including national \& international long-distance services to carriers. In the rest of the geographies, it offers $2 \mathrm{G}, 3 \mathrm{G}, 4 \mathrm{G}$ wireless services and mobile commerce.

- Company Website: www.airtel.in/

In March 2021, in the latest spectrum auction conducted by the Department of Telecom (Government of India), Bharti Airtel acquired $355.45 \mathrm{MHz}$ spectrum across the Sub GHz, mid band and $2300 \mathrm{MHz}$ bands for a total consideration of Rs. 18,699 crore (US\$ 2.55 billion). 
In February 2021, with the launch of Airtel Advertisements, a strong brand interaction solution, Bharti Airtel entered the advertising market. In February 2021, Bharti Airtel and Qualcomm Technologies, Inc. collaborated to speed up 5G deployment in India. In Hyderabad, Airtel recently became India's first telco to demonstrate $5 \mathrm{G}$ over a LIVE commercial network.

Jio: Reliance Jio is an entire ecosystem that allows Indians to live the digital life to the fullest. This ecosystem consists of powerful broadband networks, useful applications, best-in-class services and smart devices distributed to every doorstep in India. Jio's media offerings include the most comprehensive libraries and programmes of recorded and live music, sports, live and catch up television, movies and events. Jio is about creating connected intelligence for 6 billion global minds to unleash the power of a young nation. The three-pronged focus on broadband networks, affordable smartphones and the availability of rich content and applications has enabled Jio to create an integrated business strategy from the very beginning, and today, Jio is capable of offering a unique combination of telecom, high speed data, digital commerce, media and payment services.

Company Website: https://www.jio.com/

In March 2021, JioBusiness introduced an integrated offering for micro, small, and medium businesses (MSMB) to offer integrated fibre connectivity \& digital solutions.

In March 2021, Reliance Jio announced acquisition of the spectrum, gaining the right to use in all 22 circles across India. In February 2021, JioPhone successfully upgraded more than 100 million feature phone users in India to the JioPhone network, bringing a new age of transformation for feature phone users in India.

BSNL: BSNL is a technology-oriented company and provides all types of telecom services namely telephone services on wireline, wireless local loop (WLL) and mobile, broadband, internet, leased circuits and long-distance telecom service. The company has been in the forefront of technology with $100 \%$ digital technology switching network. BSNL's nationwide telecommunications network covers all district headquarters, sub-divisional headquarters, Tehsil headquarters and almost all the block headquarters.

As of April 2019, it had about 29.63-million-line basic telephone capacity, 1.39 million WLL capacity, 114.62 million GSM capacity, 31,611 fixed exchanges, 1,46,172 GSM BTSs, 95 Satellite Stations, 8,49,990 route kilometre (RKm) of OFC, 2,548 RKm of microwave network.

Company Website: http://www.bsnl.co.in/

In February 2021, at the Kadma Telephone Exchange, a Command Centre for Network Operation (CCNO) was established to ensure synergy across Bharat Sanchar Nigam Limited's (BSNL) various networks.

\section{Achievements}

Following are the achievements of the Government in the past four years: 
- Department of Telecommunication launched 'Tarang Sanchar' - a web portal sharing information on mobile towers and EMF Emission Compliances.

- Payments on unified payments interface (UPI) hit an all-time high of 2.30 billion (by volume), with transactions worth $\sim$ Rs. 4.31 lakh crore (US\$ 59.08 billion) in January 2021.

- Over $75 \%$ increase in internet coverage from 251 million users to 446 million.

\section{Road Ahead:}

Revenue from the telecom equipment sector is expected to grow to US\$26.38 billion by 2020. The number of internet subscribers in the country is expected to double by 2021 to 829 million and overall IP traffic is expected to grow four-fold at a CAGR of 30\% by 2021.

According to a Zenith Media survey, India is expected to become the fastest-growing telecom advertisement market, with an annual growth rate of $11 \%$ between 2020 and 2023 .

The Indian Government is planning to develop 100 smart city projects, and IoT will play a vital role in developing these cities. The National Digital Communications Policy 2018 envisaged attracting investment worth US\$ 100 billion in the telecommunications sector by 2022. App downloads in India is expected to increase to 18.11 billion in $2018 \mathrm{~F}$ and 37.21 billion in $2022 \mathrm{~F}$.

Note: Conversion rate used in April 2021, Rs $1=$ US\$ 0.014 
Towards Excellence: An Indexed, Refereed \& Peer Reviewed Journal of Higher Education / Mr. Bhavik Barot / Page 792-799

\title{
References
}

Media Reports and Press Releases, Cellular Operators Authority of India (COAI), Telecom Regulatory Authority of India (TRAI), Department of Telecommunication (DoT), Department for Promotion of Industry and Internal Trade (DPIIT), India Services Sector Report by Deloitte

\author{
Mr. Bhavik Barot \\ Research Scholar \\ School of Commerce, Gujarat University \\ \& \\ Dr. Gurudutta P Japee \\ Associate Professor \\ SD School of Commerce, Gujarat University, Ahmedabad
}

